\title{
O Terapeuta Ocupacional como executor de medidas socioeducativas em meio aberto: discursos na construção de uma prática
}

\author{
Aline Cristina de Morais ${ }^{a}$, Ana Paula Serrata Malfitano ${ }^{b}$ \\ ${ }^{a}$ Centro de Referência de Assistência Social - CRAS, Patrocínio Paulista, SP, Brasil.

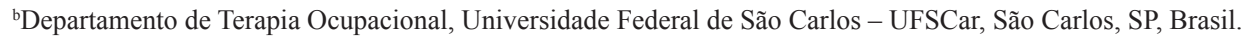

\begin{abstract}
Resumo: Introdução: A atuação do terapeuta ocupacional no campo das medidas socioeducativas com adolescentes que cometeram ato infracional ainda se mostra um tema pouco discutido nos trabalhos acadêmicos. Objetivo: Objetivou-se conhecer os terapeutas ocupacionais e as suas atuações nos serviços de medidas socioeducativas em meio aberto, no Estado de São Paulo. Método: A partir de um mapeamento dos serviços que realizam a aplicação de medida socioeducativa em meio aberto, em todos os municípios com mais de 100 mil habitantes no Estado de São Paulo, foram encontradas oito terapeutas ocupacionais em atuação. Foram realizadas entrevistas semiestruturadas com todas e, posteriormente, formou-se um grupo focal com cinco daquelas profissionais, com a finalidade de se refletir conjuntamente sobre a prática por elas executada. Os principais pontos das entrevistas foram: vínculo, olhar e atividade. Resultados: Como resultado, obteve-se que os conceitos de vínculo e olhar ainda são pouco definidos pelas profissionais, compreendidos como singularidades do trabalho do terapeuta ocupacional, com múltiplos significados. Quanto à especificidade da ação em terapia ocupacional, o uso da atividade ocupa um lugar central no discurso das colaboradoras, como um instrumento de mediação e condução do trabalho técnico, considerando-se a demanda dos adolescentes como aspecto norteador das ações profissionais. Conclusão: Conclui-se que não há uma delimitação teórica e metodológica da especificidade da prática terapêutico-ocupacional nesta área. Contudo, os resultados oferecem algumas "pistas", na medida em que o trabalho em terapia ocupacional nas medidas socioeducativas é um campo em construção, pois tem pouca representação numérica de profissionais e apresenta discursos múltiplos em seu fazer cotidiano.
\end{abstract}

Palavras-chave: Terapia Ocupacional, Prática Profissional, Sistema de Justiça, Conflito com a Lei, Adolescentes.

\section{Occupational Therapist as socioeducational measures executor in open environment: speechs to practice construction}

\begin{abstract}
Introduction: Occupational therapist practice in the socioeducational measures field involving infractors adolescents is a rare subject discussed in academic studies. Objective: This study aimed to map the occupational therapists and their work on socioeducational measures in semi open environment in São Paulo State. Method: Through the mapping of socioeducational measures services in São Paulo State in cities with populations of 100 thousand habitants and above, it was possible to identify eight occupational therapists. We applied semi structured interviews with all of them, five of them took part in a focal group, which intended to reflect about their professional practice in a collective and deepen way. The main interviews points of discussion were: "bond", "view" and "activity". Results: As results, we verified that there is a lack of definition for the "bond" and "view" concepts by the professionals which is understood by them as occupational therapists singularities, with several meanings.
\end{abstract}

Autor para correspondência: Aline Cristina de Morais, Laboratório METUIA, Universidade Federal de São Carlos, Rod. Washington Luiz, Km 235, SP-310, CEP 13565-905, São Carlos, SP, Brasil, e-mail: alinimorais@gmail.com

Recebido em Set. 9, 2015; $1^{\text {a }}$ Revisão em Nov. 22, 2015; Aceito em Jan. 25, 2016. 
As for specificity of actions in occupational therapy practice, the activity use is central in collaborator's speeches, as an instrument of practice mediation and conduction, considering adolescents' demands as an important guide of professional acting. Conclusion: We concluded that there are no theoretical and methodological boundaries from the specificity of occupational therapy practice in this field. Otherwise, the presented results offer some leads, as the occupational therapy practice in socioeducational measures is a developing field, as it is low represented by a small amount of professionals and several speeches are reported by them in their daily routine.

Keywords: Occupational Therapy, Professional Practice, Justice Administration System, Conflicts with the Law, Adolescents.

\section{Introdução}

A pesquisa que aqui se apresenta é parte dos resultados da Dissertação de Mestrado da primeira autora, a qual objetivou obter uma caracterização dos serviços de medidas socioeducativas em meio aberto, bem como mapear os terapeutas ocupacionais inscritos nesses serviços e conhecer as suas percepçóes e práticas acerca de suas atuaçóes nesses locais.

A responsabilização à prática de atos considerados ilícitos e ilegais praticados por adolescentes é prevista na legislação brasileira como uma questão a ser abordada sob uma perspectiva judicial e educativa, de responsabilidade da sociedade e do Estado. Compreende-se que, para esses casos, devem ser criadas intervençôes na esfera pública que sejam capazes de oferecer respostas para essa populaçáo e para a sociedade (SPOSITO, 2007), pautadas no direito ao acesso aos bens sociais e às sanções previstas em lei.

O Estatuto da Criança e do Adolescente - ECA (BRASIL, 1990) institui as medidas socioeducativas voltadas para adolescentes que praticarem algum ato infracional, como uma resposta estatal a fim de responsabilizá-los e protegê-los. Essas medidas podem ser privativas de liberdade, com o princípio da brevidade e excepcionalidade, como a internação e a semiliberdade, ou podem ser executadas em meio aberto, classificadas em Liberdade Assistida e Prestação de Serviços à Comunidade. A medida de internação é aplicável, segundo art. 122 do ECA (BRASIL, 1990), apenas quando $\mathrm{o}$ ato infracional corresponde à grave ameaça ou violência à pessoa, por descumprimento de outras medidas e/ou reiteraçáo no cometimento de outras infraçóes graves. Tal medida só deve ser aplicada em caráter excepcional, ou seja, devem ser priorizadas as medidas em meio aberto, pois estas também oferecem ao adolescente a possibilidade de permanecer em seu convívio social.

O Sistema Nacional de Atendimento Socioeducativo - SINASE é a lei que regulamenta e apresenta os critérios, regras e princípios para a execução das medidas destinadas a adolescentes que pratiquem ato infracional (BRASIL, 2012a). O Serviço de Proteção Social a Adolescentes em Cumprimento de Medidas Socioeducativas deve ser operacionalizado segundo a Política Nacional de Assistência Social - PNAS (BRASIL, 2005a, 2009), no âmbito das políticas públicas.

A PNAS, executada pelo Sistema Único de Assistência Social - SUAS (BRASIL, 2005a), visa a ofertar: serviços, programas e projetos de proteção social àqueles que necessitarem; acesso aos bens e serviços socioassistenciais; assegurar a convivência familiar e comunitária, bem como enfrentar as desigualdades socioterritoriais e universalizar os direitos sociais (BRASIL, 2005a). Diante disso, a estratégia de açấo da assistência social se divide em serviços de Proteção Social Básica e Proteção Social Especial.

A Proteçáo Social Básica tem o seu enfoque de trabalho envolvendo a família, com atuação nos bairros considerados vulneráveis socialmente, sendo representada por unidades de referência, denominadas Centros de Referência de Assistência Social (CRAS). O objetivo desses locais é o de prevenir situaçôes de risco por meio do fortalecimento de vínculos familiares e comunitários. Ou seja, o público-alvo são as famílias que residem na área de atuação do CRAS de um bairro, situação na qual seus vínculos familiares, comunitários e empregatícios não foram rompidos, cujas intervençôes visam a fortalecer os vínculos de solidariedade, convivência, socialização e acolhimento. Em princípio, a presença dessas unidades em bairros vulneráveis é uma estratégia para a acesso à proteçấo social básica (BRASIL, 2005b).

Já a Proteção Social Especial é voltada para aqueles que apresentam demandas específicas de situaçóes de risco, abrangendo desde o acesso a serviços de apoio e sobrevivência até a inclusão em redes sociais de suporte. São situaçóes em que famílias e indivíduos se encontram em situaçáo considerada de risco pessoal e social, tais como abandono, maus tratos, abuso sexual, uso de substâncias psicoativas, situação de rua e conflito com a lei, apresentando uma interface com o sistema judiciário (BRASIL, 
2005b). Neste tipo de proteção social, estão inseridas as medidas socioeducativas em meio aberto, classificadas em Liberdade Assistida e Prestaçáo de Serviços à Comunidade, sendo consideradas como serviços de média complexidade; e as medidas socioeducativas privativas de liberdade, como a internação e semiliberdade, com o princípio da brevidade e excepcionalidade, são consideradas como serviços de alta complexidade.

Logo, as medidas socioeducativas em meio aberto são executadas pelos serviços de média complexidade que compóem a Assistência Social (BRASIL, 2009), os quais correspondem ao acompanhamento especializado, voltado às famílias e indivíduos considerados em situaçáo de vulnerabilidade, com direitos violados, mas com a convivência familiar preservada.

A execução deste importante trabalho, que apresenta uma interface entre os sistemas jurídico e socioassitencial, é realizada, principalmente, pelos técnicos e seus dirigentes (entre outros atores), os quais caracterizam de forma significativa tais serviços. A lei não determina os requisitos específicos para ocupar esta função técnica, denominada orientador de medidas socioeducativas em meio aberto. O SINASE preconiza que a composição da equipe técnica do programa de atendimento deverá ser interdisciplinar, compreendendo, no mínimo, profissionais das áreas de Saúde, Educação e Assistência Social, de acordo com as normas de referência (BRASIL, 2012a).

As leis em vigência não apresentam um consenso legislativo para composição das equipes, além de abrangerem uma nomenclatura múltipla entre orientadores de medidas socioeducativas em meio aberto, técnicos e/ou educadores sociais (MORAIS, 2013).

Em meio às premissas do ECA e do SINASE, é necessário considerar que a composição da equipe de trabalho das medidas socioeducativas está também sob os regulamentos da assistência social. Diante disso, a resolução no 17 , de 20 de junho de 2011, do Conselho Nacional de Assistência Social (CNAS), resolve sobre as equipes que devem compor os serviços socioassistenciais. A equipe de referência básica desses serviços deve contar com o assistente social, o psicólogo e o advogado, podendo ter também a presença do antropólogo, do economista doméstico, do pedagogo, do sociólogo, do terapeuta ocupacional e do musicoterapeuta, a depender das particularidades e demandas de cada serviço (BRASIL, 2011). Vale destacar que a presença do terapeuta ocupacional nesta resolução é consequência da articulação da categoria para o reconhecimento de sua participação no SUAS e não de uma demanda profissional advinda dos serviços. Tal articulação resultou em um documento, organizado pela Associação Brasileira de Terapeutas Ocupacionais (ABRATO) e pelo Projeto METUIA ${ }^{1}$ (BARROS; CHAGAS, 2011), apresentado no Encontro Nacional dos Trabalhadores do SUAS de 2011, que aprovou a referida resolução.

A terapia ocupacional tem alcançado patamares de formalização de trabalho no campo da assistência social, a partir das experiências acumuladas na área social, bem como a articulação da categoria para tal. Isso se dá, sobretudo, em decorrência do compromisso ético-político do profissional com as populações vulneráveis para a sua inclusão social, participação e produção de bens e valores. Deste modo, pode contribuir para: prevenir a ruptura dos vínculos; aumentar a capacidade protetiva das famílias; fortalecer as relaçôes de interdependência e os vínculos familiares; favorecer o acesso às oportunidades de desenvolvimento pessoal; ampliar o acesso às redes sociais; promover reconhecimento e respeito; favorecer o pertencimento e o acesso aos bens sociais; discutir propostas e estratégias de projetos para a vida, e outras açóes em acordo com a Política Nacional de Assistência Social (ALMEIDA et al., 2012).

O campo da terapia ocupacional que tem se dedicado a fundamentar a atuação da profissão na assistência social é o social, o qual busca a ampliação de vivências e repertórios socioculturais para a vida dos sujeitos (MALFITANO, 2005). A Terapia Ocupacional Social toma por base a complexidade das trocas sociais, se dedicando à garantia de direitos que ampliem a potência das atividades no cotidiano (COSTA, 2012).

$\mathrm{Na}$ medida em que as medidas socioeducativas são voltadas aos adolescentes em conflito com a lei, dentre os serviços executados pelo setor da assistência social, destaca-se a importância de a Terapia Ocupacional Social voltar-se para a produção de saberes e práticas que se direcionem a este grupo populacional, sendo que é reconhecido que há lacunas na produção de conhecimento em terapia ocupacional neste campo (KAPPEL; GONTIJO; ALVES, 2014).

Considerando-se a escassez de pesquisas acadêmicas que abordem a atuação do terapeuta ocupacional nas medidas socioeducativas e a informaçáo de que esses profissionais têm ocupado cargos nesses serviços, o presente artigo busca contribuir com as discussões na categoria profissional acerca de sua inserção neste relevante campo de atuação. Assim, o estudo realizado objetivou mapear os terapeutas ocupacionais e conhecer a sua atuação nos serviços de medidas socioeducativas em meio aberto, voltadas para adolescentes que cometeram algum ato infracional e cumprem medida no Estado de São Paulo. 


\section{Método}

Para se alcançar o dado sobre a inserção e o número dos terapeutas ocupacionais atuantes nos serviços de medidas socioeducativas em meio aberto, foi feito um mapeamento desses locais em municípios que possuíam acima de 100 mil habitantes, no Estado de São Paulo. O recorte em cidades com mais de 100 mil habitantes ocorreu devido ao fato de a proporção de munícipes ser um critério para o recebimento de cofinanciamento do governo federal, para as medidas socioeducativas em meio aberto, com a justificativa de serem cidades com mais probabilidade de ter alto índice de violência e de desigualdade social (BRASIL, 2012b).

Para acesso aos dados, foram contatadas as Diretorias Regionais de Assistência e Desenvolvimento Social e a Coordenadoria de Ação Social, ambos órgãos de administração estadual paulista, responsáveis pela supervisão das medidas socioeducativas em meio aberto, para mapear e contatar tais serviços. Foram elencadas 129 instituiçóes cadastradas, das quais $96 \%$ de seus coordenadores responderam a um questionário sobre a caracterização dos serviços e sua equipe técnica. Verificou-se, principalmente, que a execuçấo de tais medidas ocorria pelos Centros de Referência Especializados em Assistência Social, do Sistema Único de Assistência Social, em 68\% dos casos, e que houve uma predominância dos técnicos psicólogos e assistentes sociais nas equipes, sendo que representaram $33 \%$ e $30 \%$, respectivamente. A descrição detalhada dos dados dos serviços de prestação de medidas socioeducativas em meio aberto do Estado de São Paulo encontra-se relatada em artigo prévio das autoras (MORAIS; MALFITANO, 2014).

Nesse mapeamento, foram identificados oito terapeutas ocupacionais, em quatro instituiçóes diferentes, representando sua presença em apenas $0,01 \%$ dos serviços no estado paulista, entre os municípios com mais de 100 mil habitantes. Iniciamos o contato com tais profissionais para o convite à participação em uma entrevista semiaberta. $\mathrm{O}$ intuito da realização da entrevista foi o de conhecer a atuação das terapeutas ocupacionais em serviços de medidas socioeducativas e conhecer seu discurso acerca de suas práticas neste campo.

Primeiramente, as entrevistas foram feitas individualmente, em um único encontro com cada colaboradora, ocorrendo ao final do ano de 2012, no espaço das salas de atendimento de cada instituição, com o tempo de duração de uma hora, em média, com cada uma. As entrevistas foram gravadas, transcritas e todas as colaboradoras assinaram o Termo de Consentimento Livre e Esclarecido. Foi elaborado um roteiro semiestruturado que versou sobre as açóes desenvolvidas pelas terapeutas ocupacionais e suas trajetórias profissionais, a terapia ocupacional nas medidas socioeducativas e as percepçôes acerca do adolescente que cometeu ato infracional.

Como uma segunda estratégia metodológica, posteriormente, foi realizado um grupo focal ${ }^{2} \mathrm{com}$ as terapeutas ocupacionais de uma organização não governamental, a qual representou a maioria (cinco) das profissionais entrevistadas. Nesta segunda etapa, foram discutidos, em grupo, os resultados das entrevistas feitas individualmente, utilizando o espaço para refletir de forma mais aprofundada e conjunta sobre a prática da terapia ocupacional no âmbito das medidas socioeducativas em meio aberto. Cabe destacar que a Dissertação de Mestrado, que originou este trabalho, não contém as discussões promovidas no grupo focal (somente as entrevistas), pois esta etapa foi realizada em momento posterior, contribuindo com a construção de novas categorias de análise que são aqui apresentadas.

O grupo focal, realizado em uma única sessão, teve como elemento disparador a apresentação da síntese das oito entrevistas realizadas na primeira fase. Naquela fase, foram destacados, pelas colaboradoras, o vínculo (como objetivo, facilidade e recurso do trabalho); a relação profissional com a universidade; o "olhar" do terapeuta ocupacional e suas caracterizaçôes; as especificidades da profissáo; a visáo acerca do adolescente em cumprimento de medida socioeducativa, e formas de gestão do serviço. O grupo foi orientado por um roteiro semiestruturado de elaboraçáo das autoras. Dentre os temas discutidos, destacaram-se a reflexão acerca de qual a singularidade do trabalho da terapia ocupacional nas medidas socioeducativas; a atuaçáo da profissão a partir do Sistema Único de Assistência Social; a contradição do papel do técnico (entre o controle judicial e a abordagem educativa); os objetivos do acompanhamento; o vínculo; o "olhar", e a rede de atendimento.

As entrevistadas foram identificadas pela letra E, com numeraçáo de um a oito para diferenciá-las entre si, a fim de preservar as suas identidades, e as participantes do grupo focal, com a letra G, com numeraçáo de um a cinco ${ }^{3}$. A análise dos dados foi feita por meio da organização de categorias/temas para discussão que ocuparam a maior parte dos relatos e das discussóes nas entrevistas e no grupo focal, a partir da transcrição das gravações de áudio realizadas através da coleta de dados. As categorias de destaque eleitas para análise foram: o vínculo, o olhar e a atividade. 


\section{Resultados e Discussão}

O pequeno número de terapeutas ocupacionais encontrado em atuaçáo nos serviços que executam as medidas socioeducativas demonstra a recente incorporação do profissional na composiçáo oficial dos serviços socioassistenciais, bem como destaca a necessária luta para ocupar tais espaços, se a categoria considerar esta uma frente importante de ampliação de postos de trabalho e da profissão. Para tanto, como destacam Lopes e Pan (2013), ainda há o desafio de que os cursos de graduaçáo enfoquem os conteúdos de Terapia Ocupacional Social, não priorizando, somente, abordagens que concernem à área da saúde.

Nos serviços em que foram encontradas as terapeutas ocupacionais em atuação, suas contrataçóes ocorreram em decorrência da relação próxima que aqueles equipamentos mantiveram com universidades com cursos de graduaçáo em terapia ocupacional, seja por meio de estágios ou de práticas de extensão ali realizados. Deste modo, a parceria com a universidade favoreceu a contratação de terapeutas ocupacionais nos serviços de medidas socioeducativas, demonstrando que a universidade ainda exerce um papel relevante na criação, ampliação e consolidação de espaços profissionais, quando executa açôes de ensino, pesquisa e extensão (LOPES et al., 2012a).

Todas as terapeutas ocupacionais que compuseram o grupo focal trabalham em uma organização não governamental, em um município de grande porte do Estado de São Paulo; a maioria delas apresenta pós-graduação lato sensu nas seguintes áreas: reabilitação, saúde mental, social (especificamente no campo do adolescente em conflito com a lei) e pedagogia (MORAIS, 2013).

Nas entrevistas e no grupo focal, foi possível notar que se trata de profissionais interessadas em dialogar sobre as questóes sociais, de modo geral, e sobre a terapia ocupacional no universo das medidas socioeducativas, em particular. Todas elas falaram sobre a falta de materiais bibliográficos sobre a temática e o desejo de compartilhar experiências e buscar o aprimoramento de seu trabalho.

\subsection{A singularidade do terapeuta ocupacional em seu discurso e a atuação junto aos adolescentes em cumprimento de medida socioeducativa em meio aberto}

A análise tecida discorre em torno dos relatos oferecidos pelas participantes, sendo que estes podem se mostrar diversos em outras realidades. Vale ressaltar que o intuito não foi o de avaliar as práticas de tais profissionais, mas sim aproximarmo-nos dos discursos acerca da prática terapêutico-ocupacional realizada e ampliar as possibilidades e espaços de diálogo acerca dessa temática, ainda pouco discutida.

Apesar de verificado que as terapeutas ocupacionais desempenham funçôes correlatas com as dos demais técnicos, elas consideram que trazem importantes contribuiçôes aos serviços, ligadas à especificidade da sua profissão, sobretudo com relação ao uso das atividades como um recurso para operacionalização do trabalho com o adolescente (MORAIS, 2013).

A atuação do terapeuta ocupacional na área social ocorre a partir de sua interpretação acerca da demanda dos sujeitos individuais e coletivos:

Ainterpretação éseguida de sua problematização, do estudo do contexto e da elaboraçáo de projeto que envolve negociação constante. É nesse sentido que as noções de cidadania e de produçáo de identidades são guias da interpretação e da formulação de projetos de intervenção (BARROS, 2004, p. 93).

Definir o papel deste profissional no serviço requer um acúmulo de conhecimento que possibilite formas de experimentação e produção de conhecimento sobre metodologias de intervenção que enfoquem a inserção social, por meio da autonomia e da participação dos adolescentes. Kappel, Gontijo e Alves (2014) inferem que ainda falta uma compreensáo pelas equipes dos serviços acerca do trabalho em terapia ocupacional, embora apontem que essa é uma questão presente em todas as subáreas de atuação da profissão.

Parte-se da compreensão de que o ato infracional de adolescentes na sociedade brasileira requer uma compreensão macrossocial, na medida em que é permeado por questóes de classe social (BORBA, 2012; SALIBA, 2006). Sob esta perspectiva, os objetivos da intervençáo proposta pelos terapeutas ocupacionais junto às medidas socioeducativas devem ter como base principal o campo social, na medida em que é nele que reside o fenômeno e que é este que contém aportes metodológicos para os fins de garantia dos direitos de cidadania, emancipação, autonomia e fortalecimento das redes sociais de suporte para aquela população.

Uma profissional colaboradora relatou que, dentre os objetivos de suas ações, estaria "tentar afastar o menino da questão da infração, das situaçóes ilícitas e de risco e vulnerabilidade" (E7), podendo dar margem para uma compreensão "culpabilizadora" da questão. Por esse motivo, o relato foi levado à discussão no grupo focal. 
De modo geral, as terapeutas ocupacionais defenderam que os objetivos do trabalho seguem para além do afastamento das situaçóes ilegais, pois, antes do ato infracional em si, houve, predominantemente, um histórico de não acesso aos bens sociais que acabaram desembocando no encaminhamento ao serviço de medida socioeducativa.

Vê-se, portanto, que as ações voltadas aos adolescentes, executadas pelos técnicos, especificamente das medidas socioeducativas, ocupam um lugar de contradição, na medida em que, ao mesmo tempo em que se deve protegê-los integralmente e promover sua autonomia, por meio de uma ação educativa, há um controle de seus comportamentos, com vistas à manutenção da ordem e afastamento do "crime", determinado por uma medida judicial. A contradição é inerente à ordem social; entretanto, reconhecendo-a, abrem-se as possibilidades para o debate em questão. A complexidade dessa temática está no interior dessa dualidade, dificultando a sua compreensão e ação por parte dos técnicos.

\begin{abstract}
A prática [do ato infracional] não é exclusiva do adolescente, a prática infracional está relacionada à falta de escola, como foi de escola, saúde, por falta de cuidado, então o ato infracional é um sintoma, uma consequência, então, eu imagino que, quando a pessoa diz que é dificil tirar a prática infracional do adolescente, eu falo que é impossivel, se a gente não ver as outras coisas (G2).
\end{abstract}

Nesse sentido, G4 infere que, quando o adolescente chega ao serviço de medidas socioeducativas, há uma série de "consequências" e acessos sociais (os quais não foram cuidados antes) que precisam ser abordados; contudo, o serviço não consegue (e nem deve) fazê-lo sozinho.

Considerando-se que a ação em terapia ocupacional social visa à emancipação, à busca de autonomia dos sujeitos e, portanto, à liberdade de escolha (BARROS; LOPES; GALHEIGO, 2007), e que isso pode implicar em decisóes, no caso dos referidos adolescentes, pode ser que estas náo sejam necessariamente aquelas esperadas pela sociedade ou pelos técnicos. E, ainda, a autonomia e o direito de escolha se dão quando há algumas opçóes, as quais muitas vezes não se apresentam para esses adolescentes.

Assim, tentar "afastar o menino da infração" e mudá-lo não correspondem à busca de sua autonomia, pois esta pode se expressar sob diversas formas e açôes, mesmo que de modos náo legitimados. Cada pessoa, grupo social ou comunidade precisa "descobrir, a seu modo, as dimensóes e possibilidades da realidade" (BARROS; LOPES; GALHEIGO, 2007, p. 352).
Portanto, mais do que reprimir a prática do ato infracional, o terapeuta ocupacional pode buscar ampliar as possibilidades de escolhas de trajetórias para aqueles adolescentes.

Compreendendo-se que a infração está associada às questóes sociais, à falta de acesso à escola e outros cuidados setoriais, houve, no grupo focal, um consenso de que um aspecto que dificulta o cumprimento dos objetivos de garantir os direitos dos adolescentes é a relação com a rede de serviços, que deveria garantir esses "cuidados" da educação, da saúde, do trabalho, mas não o fazem de forma adequada.

G1 relatou:

Se a gente for falar do objetivo dos programas, o objetivo que comę̧a a ser descrito é que o adolescente e a sua familia possam se desenvolver, buscar sua cidadania e, portanto, que eles busquem, que a gente possa superar a prática do ato infracional, ela pode ser uma consequência, ou não [...]. Se a gente for considerar, infracionar ou não, éperverso, por tudo isso. A gente escreve um relatório desse jeito para o judiciário deixando claro e sugerindo por outros tipos de avanço e ele aceita, acho que isso já mudou um pouco (G1).

O relato supracitado evidencia que a profissional considera a sua atuação como uma busca de proteção dos adolescentes (como descreve a própria tipificação do serviço), no sentido da busca pela cidadania e garantia dos direitos, e que, se alcançar esse objetivo, poderá contribuir para a superação do envolvimento com atos infracionais por parte do adolescente.

\subsection{A singularidade do terapeuta ocupacional em seu discurso: o vínculo, o olhar e a atividade}

\subsubsection{Vínculo}

Nas entrevistas realizadas individualmente com as terapeutas ocupacionais dos serviços de medidas socioeducativas em meio aberto, quando perguntado sobre o que seria objetivo, facilidade e recurso de trabalho dos terapeutas ocupacionais em suas práticas, para as três diferentes questóes, a resposta majoritária foi o vínculo.

$\mathrm{O}$ vínculo se baseia nas relaçóes de confiança, quando um sujeito é significativo para o outro, configurando uma relação de proximidade e de interdependência. Segundo Pichon-Rivière (1988), o vínculo se constitui na interação complexa entre um sujeito e uma representação de um objeto externo, de forma dialética e singular a cada situação. É a partir dele que se torna possível o acesso às reais 
demandas e necessidades da população (LOPES; BORBA; CAPPELARO, 2011).

Há uma multiplicidade de sentidos atribuídos pelas terapeutas ocupacionais para o uso e significados do vínculo com a população atendida:

Eu acho que um dos objetivos mais importantes é a vinculação, com o adolescente e com a família, porque, a partir de um bom vínculo construido, é possivel compreender melhor o que está acontecendo e refletir melhor como adolescente e a familia sobre as situaçôes (E8).

Malfitano (2005) compreende o vínculo como elemento central no núcleo de ação da Terapia Ocupacional Social, podendo as atividades serem facilitadoras para a busca da construção conjunta de novos projetos de vida. Ainda, neste campo da profissáo, a importância do vínculo se deve ao fato de que, na ausência dele, não se consegue acessar as reais demandas, as necessidades e os desejos das pessoas, resultando no insucesso das intervençóes.

A profissional G2 considera o vínculo como o ponto de partida de um acompanhamento na área social, baseado na relação de confiança que se estabelece. Referiu que o vínculo se forma em uma via de mão dupla, na medida em que o adolescente traz a sua história de vida e o técnico busca fortalecer a relação de confiança ali estabelecida. Ainda, a colaboradora afirmou que o vínculo se define também como um recurso de trabalho e um objetivo das suas açóes. Ou seja, colocou o vínculo como ponto de partida, recurso e objetivo do trabalho terapêutico-ocupacional.

Já G1 buscou justificar os motivos que levam a essa "mistura" do uso do conceito de vínculo, alegando que a sua ausência é responsável pela falta do adolescente nos atendimentos, bem como sua presença justifica a busca do orientador pelo adolescente nas situaçóes difíceis de sua vida, além do bom andamento das atividades desenvolvidas.

Como "ponto de partida" para o trabalho, as terapeutas ocupacionais apontaram que o vínculo é fundamental para adesão do adolescente ao acompanhamento, "amenizando" o viés da obrigatoriedade da medida judicial:

De fato, por mais que essa medida seja obrigatória, por mais que o adolescente e a familia saibam que, se ele não cumprir as sançôes, uma delas é a privação de liberdade, não é isso que faz eles virem ou não na medida. O adolescente sempre banca, se ele não quiser vir ele não vem e ele banca. Então a gente só consegue ampliar o trabalho se a gente se colocar mesmo próximo, ao lado, tem que seduzir e abrir que é algo importante pra vida dele (G1).
A medida judicial é bem carregada de que o menino é obrigado a estar aqui. Então a gente tenta o tempo todo propiciar algo que seja do desejo dele, que ele possa ter prazer em estar aqui. A gente tem que desconstruir esse viés, por mais que seja uma intervenção social, a gente vai tentar fazer que seja um ambiente que ele aproveite e seja positivo, o vinculo tem muito esse papel aqui (G4).

Assim, as terapeutas ocupacionais apresentaram a visão de que, apesar de as medidas socioeducativas serem obrigatórias, seria o vínculo (e não a obrigação) que faria os adolescentes cumprir a medida. $\mathrm{Ou}$, ainda, já que eles estão sob ação judicial, que possam se identificar minimamente com a equipe técnica e com a instituição.

Todavia, destaca-se que tanto a relaçáo judicial como a "socioeducativa" se mostram ambivalentes, haja vista que são permeadas por uma responsabilização cujo cumprimento é obrigatório, mesmo que pautada em uma lógica socioeducativa prevista em lei.

Quando se buscou compreender como ocorre o processo de vinculaçáo com os adolescentes, o tempo e a escuta foram considerados fatores para o seu estabelecimento, e destacados pelas terapeutas ocupacionais entrevistadas como aprendizados decorrentes de sua formação profissional:

A gente também não consegue isso no primeiro contato, a gente precisa de um tempo pra isso. É nesse tempo que a gente vai, com certeza, descortinar as açôes junto pra ir fortalecendo esse vinculo [...]. A formação do TO ela é ampla e ela possibilita você entrar em contato com o sujeito e a sua diversidade de uma forma bem próxima, eu acho que a formação ela traz isso. Então acho que a gente aprende a ter escuta, o que é escuta, você já trabalha isso desde o comę̧o, acho que o toque, sabe essa coisa mais próxima? (G4).

A facilidade na "escuta" e o respeito à diversidade, elementos considerados centrais para o estabelecimento do vínculo com os adolescentes, foram aferidos por G4 como uma particularidade da formação do terapeuta ocupacional.

Diante das falas proferidas com relação ao vínculo, permaneceu um discurso generalista de que este é determinante nas açóes da terapia ocupacional nas medidas socioeducativas, acabando por não se definir, com um rigor necessário à profissão, o que são (além do vínculo) os objetivos e os recursos da terapia ocupacional. Parte dessas contradiçôes vem da profissão ocupar um território fronteiriço, "que imprime marcas em nossa prática”, embora seja necessário construir as nossas singularidades num campo de multiplicidades (LIMA, 1997, p. 99). 
Além disso, o vínculo foi referido quase como um conceito autoexplicativo e somente positivo nos acompanhamentos realizados. Entretanto, acreditamos que o vínculo pode não ser somente favorável na relaçáo de acompanhamento profissional, na medida em que ele pode se configurar sob diversas naturezas (afetiva, relacional, autoritária, controladora, maternal, caritativa, entre outras). Portanto, a delimitação do conceito de vínculo se mostrou generalista e contraditória, ao passo que, na prática, está pouco fundamentada.

\subsubsection{Olhar}

Assim como o vínculo, o "olhar" do terapeuta ocupacional foi um dos aspectos mais apontados pelas entrevistadas como uma "especificidade" da profissão, no âmbito das medidas socioeducativas. O "olhar" foi atribuído como algo específico deste profissional, significando tanto a diversidade que se faz presente na formação em terapia ocupacional quanto a visão holística dos sujeitos por parte deste profissional.

Consideram o "olhar" como uma característica singular da terapia ocupacional, a qual permite que o profissional tenha uma dimensão dos aspectos sentimentais, relacionais, sociais, educacionais, de saúde, enfim, "do todo" (G3) da vida dos sujeitos. Além disso, mostram, em seus relatos, que a formação intersetorial, ou seja, que transita entre áreas diversas, permite que o terapeuta ocupacional seja singular e diferenciado.

Sobre esse olhar que a gente tem lá na graduação, olhar da sauide mental, na psicologia, e até também no social, eu acho que isso amplia o nosso trabalho, a gente consegue pontuar junto com o adolescente essas coisas que talvez outra pessoa não faça (G5).

Assim como todo mundo, eu acho que está na formação esse olhar, é a formação, o perfil, a grade e todas as especificidades da nossa formação eu acho que traz esse olhar diferenciado, tem a atividade, que é a formação da TO, é a AVD, tem o cotidiano, enfim, acho que tem a ver com a nossa formação (G4).

Segundo Lima (2004, p. 44) a percepção visual, caracterizada pelo olhar, é algo que vai além dos aspectos fisiológicos, pois é subjetivo e cultural, sendo que somente "vemos aquilo sobre o que debruçamos". Ou seja, aquilo que o sujeito pensa e entende do mundo determina a forma que ele vê.

O "olhar", para além de ver, requer uma participação e integração com aquilo a que nos dirigimos. Assim, o terapeuta ocupacional também precisa perceber e buscar nas imagens mais cotidianas e mais comuns aquilo que nelas há de inusitado, de novo, de diferente, de interessante, de singular. Para isto talvez seja preciso pensar, agir e olhar no cotidiano como o faria um estrangeiro: estranhar e se encantar com cada nova revelação (LIMA, 2004, p. 45).

Deste modo, segundo Lima (2004), o ato de "olhar" não está intrínseco aos terapeutas ocupacionais, pois, o profissional pode se prender a procedimentos fragmentados e sistematizados que aprisionam o olhar, náo dando margem para a experiência do fazer e da percepção do "invisível". A autora supracitada conceitua o "olhar" de um modo diferente das entrevistadas, na medida em que o considera em uma perspectiva antropológica, de "estranhamento" do outro, para que se possa, de fato, conhecê-lo e se aproximar dele, sem pré-julgamentos.

Portanto, o "olhar" não está somente na terapia ocupacional, já que outros profissionais podem tê-lo, não se configurando como uma especificidade da profissão. Sua ação, que inclui seu "olhar", certamente pode contribuir para uma prática mais humanizada no ambiente institucional de aplicação das medidas socioeducativas, favorecendo a reinserção do adolescente na família e na comunidade, criando novos projetos de vida, bem como facilitando a intersetorialidade e o trabalho em rede (KAPPEL; GONTIJO; ALVES, 2014).

\subsubsection{Atividade}

Outro aspecto ressaltado pelas terapeutas ocupacionais, como um diferencial técnico em relação aos demais profissionais da equipe de trabalho, foi o uso de atividades.

$O$ uso da atividade como recurso, como instrumento de intervenção é algo que cola muito bem com adolescência, que fala pelo concreto, que fala pelo não-verbal, então acho que a gente ganha, a gente sai na frente, porque a gente consegue conversar com esse adolescente, com a prática do ato infracional pela atividade sem trocar uma palavra. Então, acho que esse é um grande diferencial (...) a terapia ocupacional tem essa facilidade de trabalhar a coisa mesmo de visualizar as suas atividades, a sua rotina, como construir isso, como melhorar isso. Eu vejo que as terapeutas ocupacionais sentam com os meninos e falam assim: Me conta, o que você faz do seu dia? E a sua semana? Como é sua manhã? Como é sua tarde? Como é sua noite? Como é sua madrugada? Mas pra quem está querendo voltar a estudar, como é que faz? Vai poder ir na noitada todo dia? Então essa coisa de trabalhar 
com o mapa das atividades, do cotidiano, com isso também é outro ponto de partida interessante e se diferencia das outras profissóes (G1).

Nota-se que a atividade representa múltiplos sentidos, a partir deste relato, na medida em que esta é considerada um instrumento-recurso que dialoga bem com as diversas linguagens (não somente verbais) da adolescência, bem como no direcionamento das açóes para a rotina e o cotidiano.

Segundo Galheigo (2003, p. 108), a incorporação do conceito de cotidiano no discurso da prática traz uma mudança radical na proposição teórico-metodológica da terapia ocupacional, a qual se funda na "retomada histórica e contextualizada do sujeito e sua inserção participante no coletivo", considerando a subjetividade e os significados que os sujeitos dáo às suas experiências e sua realidade social.

O comando de uma atividade no processo grupal e um processo individual. A terapia ocupacional náo é intervencionista verbal na condução da atividade, os outros profissionais, muitas vezes eles atropelam, eles conduzem mais pro seu jeito pessoal de fazer. Acho que a TO vai mesmo conduzindo de uma forma em que o próprio menino vai tendo as suas próprias respostas através do fazer, eu acho que isso é muito diferente (G1- grifo nosso).

Apesar de reconhecerem que o uso de atividade não é exclusivo do terapeuta ocupacional, consideram que ele a usa de uma forma "melhor", "mais propositiva" e que cada profissional a utilizará com um "viés" (E3) (ou olhar? ou objetivo?) diferente.

G1 considerou que algumas intervençôes específicas, tal como o grupo de patchwork com as mães, que ocorria naquela instituição, deviam necessariamente ser executadas pelos terapeutas ocupacionais, em decorrência do "diferencial na execução da atividade". Porém, seu discurso para justificar tal posicionamento apresenta uma série de argumentos e o reconhecimento de outros profissionais também envolvidos com atividades.

Entretanto, ela não é exclusiva e, outros profissionais podem usar. Muitas vezes com adolescentes é necessário, é um caminho, para ele também poder fazer a intervenção mais especifica dele. Por isso, eu acho que fica psicólogo e assistente social com as atividades? Sim, às vezes fazem (G1).

Apesar de as entrevistadas terem reconhecido que todos os profissionais utilizam as atividades com os adolescentes no programa de medidas socioeducativas, permaneceu a defesa de que o terapeuta ocupacional o faz diferente, com um "olhar" (novamente) mais especial:
Então, tem algumas coisas que todos fazem, porém acho que a gente volta pra questão do olhar, que é diferente quando você está ali, e não é só o TO, cada profissional nos atendimentos individuais, nas suas abordagens, você coloca um olhar mais voltado pra sua profissáo. Agora, quando eu olho pro macro eu vejo isso muito igual mesmo $e$ as diferenças são que cada profissão tem o seu individual, a sua proposta e a sua ação mais específica (G4 - grifo nosso).

O relato acima se referiu ao "olhar" no sentido de enfoque nas especificidades das profissóes, em contrapartida com aquilo que é geral, do serviço, do "macro". Nesse sentido, é necessário considerar que muitas açôes dos terapeutas ocupacionais nas medidas socioeducativas são correlatas às atribuiçôes gerais de um orientador de medidas (MORAIS, 2013).

Lima (1997) reconhece que a singularidade da terapia ocupacional encontra-se no trânsito entre fronteiras, lidando com indivíduos que habitam as margens da sociedade, sendo que a utilização de atividades caracteriza-se como meio para se alcançarem os objetivos de cada campo específico.

\section{Conclusão}

A terapia ocupacional no campo das medidas socioeducativas em meio aberto no Estado de Sáo Paulo tem sido desenhada pelas profissionais entrevistadas em suas práticas. Evidenciaram que a singularidade da ação terapêutico-ocupacional ainda se mostra bastante tímida, senão inexistente. Diante disso, é preciso refletir e fundamentar-se acerca dessa área de atuação profissional, para além da caracterização pouco aprofundada do "olhar da terapia ocupacional”, em busca de um embasamento teórico-prático consistente. Com dados empíricos de acompanhamento de práticas neste campo, sabe-se da contribuição dos terapeutas ocupacionais junto aos adolescentes; entretanto, o fortalecimento deste trabalho carece de uma maior sustentação teórica para seu delineamento.

Como ressaltam Tedesco e Liberman (2008, p. 255), a produção da terapia ocupacional tem pontos positivos, como:

[...] a diversidade, o conhecimento em ação e os diálogos com diferentes áreas do conhecimento. Porém, temos uma grande desvantagem: a falta de sistematizaçấo.

Conforme mencionamos acima, o documento publicado pela Associação Brasileira de Terapeutas Ocupacionais, em parceria com o Projeto METUIA 
(BARROS; CHAGAS, 2011), na ocasiáo do Encontro Nacional dos Trabalhadores do SUAS, em 2011, visou a elucidar as principais açôes do terapeuta ocupacional no contexto dos serviços e programas da assistência social, incluindo açóes nos programas de aplicação de medidas socioeducativas em meio aberto. De modo geral, é explicitado como trabalho do terapeuta ocupacional: compreender o significado do ato infracional na trajetória do adolescente; usar a atividade como mediação e leitura da dinâmica social para a construção de laços de confiança; organizar projetos futuros; compreender seu cotidiano, e buscar estratégias ligadas ao pertencimento familiar e grupal, entre outras. A atividade pode ser aplicada como um instrumento de emancipação e autovalorização, favorecendo a ampliação de espaços socioculturais que contribuam para conscientização dos direitos e deveres. Ainda, é ressaltada a importância das equipes multidisciplinares e a atuaçáo junto à rede de serviços de atenção aos adolescentes, compreendendo o ato infracional como parte do cenário político, econômico e social brasileiro (BARROS; CHAGAS, 2011).

Tendo-se por base as proposiçóes acima elencadas, nota-se uma proximidade com os relatos das terapeutas ocupacionais colaboradoras com a presente pesquisa, na medida em que afirmaram a necessidade de retirada do enfoque no ato infracional em si, para colocar o objetivo do trabalho pautado na trajetória do adolescente e seu percurso de vida, tendo como base o sistema de garantia de direitos previsto em lei.

Quanto à especificidade da ação em terapia ocupacional, o uso da atividade ocupou um lugar central nos discursos, como um instrumento de mediação social, condução do trabalho técnico, pertencimento e diferencial na equipe multidisciplinar. Consideraram que a demanda trazida pelos adolescentes é um aspecto importante na definiçẫo das atividades e dos objetivos das práticas.

Assim, podemos interpretar que o destaque das entrevistadas ao "olhar" terapêutico-ocupacional relaciona-se ao objetivo de sua ação, podendo estar impregnado de duas ênfases: a representação de uma perspectiva antropológica da alteridade, ligada ao fazer, ao processo, aos meios, ao que parece invisível aos olhos, mas repleto de significados (LIMA, 2004), bem como a falta de embasamento teórico-metodológico que justifique e sustente a prática neste campo.

Conclui-se, portanto, que a prática em terapia ocupacional na assistência social é um campo em construção, sobretudo na área das medidas socioeducativas junto a adolescentes, pois tem se mostrado pouco representativa numericamente e com discursos múltiplos em seu fazer cotidiano.
A terapia ocupacional alcançou novos patamares de formalização na assistência social; entretanto, ainda há desafios a serem enfrentados com relaçáo ao fortalecimento de sua articulaçáo com os trabalhadores da área. Sua institucionalização e seu reconhecimento dependerão do desenvolvimento e das lutas empreendidas pela categoria, bem como pela sua capacidade de responder, a partir de sua especificidade, às necessidades sociais da população (ALMEIDA et al., 2012).

O desafio que se coloca, especificamente em relação à atuação da terapia ocupacional nas medidas socioeducativas, é que os profissionais se fortaleçam na legitimidade de sua contribuição social junto a esta população. Faz-se necessário que se estabeleça um diálogo entre a perspectiva macrossocial, em busca de referenciais do campo social para o desenvolvimento de uma compreensão do fenômeno contemporâneo e seu enlace na sociedade, e a perspectiva microestrutural, relativa ao cotidiano de ações com a população-alvo, tendo como base o fazer diário e sua constituição da vida social (MALFITANO, 2005).

O relato de que o terapeuta ocupacional "não é intervencionista verbal na condução da atividade" (G1) oferece algumas "pistas" para pensar na prática profissional junto aos adolescentes, o que torna necessária a ampliação de repertório de recursos, de atividades, criatividade e atualização do terapeuta ocupacional no campo social, pressupondo outros canais de comunicação. O uso de recursos midiáticos e ferramentas da internet, por exemplo, tem se mostrado uma potente forma de comunicação com os jovens, propiciando a criação de lugares de pertencimento, acesso à cultura, ao lazer, à comunicação e à tecnologia, expandindo a participaçáo social/territorial e as fronteiras socioculturais (SILVA; CARDINALLI; LOPES, 2015).

Durante as entrevistas, foram citadas algumas atividades que as profissionais desenvolveram com os jovens, tais como levá-los na pista de skate, oferecer oficina de grafite e de rádio, na qual os adolescentes gravaram e compuseram um rap. Tais açóes exemplificam que elas devem ser pensadas tendo como base o universo sociocultural, de identificação e pertencimento dos sujeitos, mas também que possibilitam a criação de novos universos, permitindo assim um maior alcance da formação para a promoção da autonomia e construçáo de projetos. O desafio que se coloca é o de garantir que tais açóes tenham ressonâncias nas trajetórias de vida, mesmo após o cumprimento da medida socioeducativa.

Cabe ainda assinalar a relevância de se compreender a atuação política como um recurso de trabalho 
em terapia ocupacional social, na medida em que a discussão dos serviços que atendem a esta população, a rede de atendimento, a intersetorialidade, bem como a disponibilidade de instrumentos para acesso aos bens sociais, são importantes recursos de ação técnica (LOPES et al., 2014). Nenhuma colaboradora remeteu-se a este enfoque na sua intervenção; contudo, considera-se um elemento de essencial abordagem para a discussão acerca do papel profissional do terapeuta ocupacional no campo social.

Trata-se, por fim, de estar em um território de fronteira, trazendo o desafio do diálogo entre margens, da contribuição social, das profissionalidades e, principalmente, das perspectivas para a atuaçáo técnica e política para o efetivo desenvolvimento da socioeducação para esses adolescentes.

\section{Referências}

ALMEIDA, M. C. et al. Processos e práticas de formalização da Terapia Ocupacional na Assistência Social: alguns marcos e desafios. Cadernos de Terapia Ocupacional da UFSCar, Sáo Carlos, v. 20, n. 1, p. 30-41, 2012.

BARROS, D. D. Terapia Ocupacional social: O caminho se faz ao caminhar. Revista de Terapia Ocupacional da Universidade de São Paulo, São Paulo, v. 15, n. 3, p. 90-97, 2004.

BARROS, D. D.; CHAGAS, J. N. M. (Org.) Terapia Ocupacional: atuaçáo na assistência social e no desenvolvimento socioambiental, socioeconômico e cultural. Brasília: ABRATO, 2011.

BARROS, D. D.; LOPES, R. E.; GALHEIGO, S. M. Terapia Ocupacional Social: concepções e perspectivas. In: CAVALCANTI, A.; GALVÃO, C. Terapia Ocupacional: fundamentação \& prática. Rio de Janeiro: Guanabara Koogan, 2007. p. 347-343.

BORBA, P. O. L. Juventude marcada: relaçôes entre ato infracional e a escola pública em São Carlos - SP. 2012. 250f. Tese (Doutorado em Educação) - Universidade Federal de São Carlos, São Carlos, 2012.

BRASIL. Lei no 8.069, de 13 de julho de 1990. Estatuto da Criança e do Adolescente. Diário Oficial [da] República Federativa do Brasil, Brasília, DF, 16 jul. 1990.

BRASIL. Ministério do Desenvolvimento Social e Combate à Fome. Política Nacional de Assistência Social PNAS/2004 e Norma Operacional Básica NOB/SUAS. Brasília, 2005a.

BRASIL. Ministério do Desenvolvimento Social e Combate à Fome. Resoluçáo no 130, de 15 de julho de 2005. Aprova o Sistema Único de Assistência Social - SUAS. Diário Oficial [da] República Federativa do Brasil, Brasília, DF, 12 set. 2005b. Seção 1, p. 81.

BRASIL. Ministério do Desenvolvimento Social e Combate à Fome. Resolução no 109, de 11 de novembro de
2009. Aprova a Tipificação Nacional de Serviços Socioassistenciais. Diário Oficial [da] República Federativa do Brasil, Brasília, DF, 25 nov. 2009.

BRASIL. Resolução no 17, de 20 de junho de 2011. Ratificar a equipe de referência definida pela Norma Operacional Básica de Recursos Humanos do Sistema Único de Assistência Social - NOB-RH/SUAS e reconhece as categorias profissionais de nível superior para atender as especificidades dos serviços socioassistenciais e das funçôes essenciais de gestão do Sistema Único de Assistência Social-SUAS. Diário Oficial [da] República Federativa do Brasil, Brasília, DF, 21 jun. 2011. Seção 1.

BRASIL. Lei no 12.594, de 18 de janeiro de 2012. Institui o Sistema Nacional de Atendimento Socioeducativo (Sinase), regulamenta a execução das medidas socioeducativas destinadas a adolescente que pratique ato infracional; e altera as Leis nos 8.069, de 13 de julho de 1990 (Estatuto da Criança e do Adolescente); 7.560, de 19 de dezembro de 1986, 7.998, de 11 de janeiro de 1990, 5.537, de 21 de novembro de 1968, 8.315, de 23 de dezembro de 1991, 8.706, de 14 de setembro de 1993, os Decretos-Leis nos 4.048, de 22 de janeiro de 1942, 8.621, de 10 de janeiro de 1946, e a Consolidação das Leis do Trabalho (CLT), aprovada pelo Decreto-Lei no 5.452, de 1o de maio de 1943. Diário Oficial [da] República Federativa do Brasil, Brasília, DF, 19 jan. 2012a.

BRASIL. Ministério do Desenvolvimento Social e Combate à Fome. Portaria no 222, de 30 de junho de 2008. Dispóe sobre o co-financiamento Federal do Piso Fixo de Média Complexidade para a implantação do CREAS e implementação do Serviço de Proteção Social aos Adolescentes em Cumprimento de Medidas Socioeducativas em Meio Aberto no âmbito da Proteção Social Especial do Sistema Único de Assistência Social - SUAS, com recursos do Fundo Nacional de Assistência Social. Diário Oficial [da] República Federativa do Brasil, Brasília, DF, 01 jul. 2008. Disponível em: <www.sedest.df.gov.br>. Acesso em: 13 ago. 2012b.

COSTA, S. L. Terapia Ocupacional Social: dilemas e possibilidades da atuação junto a povos e comunidades tradicionais. Cadernos de Terapia Ocupacional da UFSCar, São Carlos, v. 20, n. 1, p. 43-54, 2012.

GALHEIGO, S. M. O Cotidiano na Terapia Ocupacional: cultura, subjetividade e contexto histórico-social. Revista de Terapia Ocupacional da USP, São Paulo, v. 14, n. 3, p. 104-109, 2003.

KAPPEL, V. B.; GONTIJO, D. T.; ALVES, H. C. As açóes do terapeuta ocupacional na rede de atençáo aos adolescentes em conflito com a lei. Revista Brasileira Adolescência e Conflitualidade, Sáo Paulo, n. 10, p. 6186, 2014.

KIND, L. Notas para o trabalho com a técnica de grupos focais. Psicologia em Revista, Belo Horizonte, v. 10, n. 15, p. 124-136, 2004.

LIMA, E. A. Terapia Ocupacional: Um território de fronteira? Revista de Terapia Ocupacional da USP, São Paulo, v. 8, n. 2/3, p. 98-101, 1997. 
LIMA, E. M. F. A. A análise de atividade e a construção do olhar do terapeuta ocupacional. Revista de Terapia Ocupacional da USP, São Paulo, v. 15, n. 2, p. 42-48, 2004.

LOPES, R. E. et al. Occupational Therapy professional education and research in the social field. World Federation of Occupational Therapy - WFOT Bulletin, Austrália, v. 66 , n. 1, p. 52-57, $2012 \mathrm{a}$.

LOPES, R. E. et al. Terapia Ocupacional no campo social no Brasil e na América Latina: panorama, tensóes e reflexôes a partir de práticas profissionais. Cadernos de Terapia Ocupacional da UFSCar, São Carlos, v. 20, n. 1, p. 21-32, 2012 b.

LOPES, R. E. et al. Recursos e tecnologias em Terapia Ocupacional Social: açóes com jovens pobres na cidade. Cadernos de Terapia Ocupacional da UFSCar, São Carlos, v. 22, n. 3, p. 591-602, 2014.

LOPES, R. E.; BORBA, P. L. O.; CAPPELARO, M. Acompanhamento individual e articulaçáo de recursos em Terapia Ocupacional social: compartilhando uma experiência. O Mundo da Saúde, São Paulo, v. 35, n. 2, p. 233-238, 2011.

LOPES, R. E.; PAN, L. C. O ensino de terapia ocupacional social. Revista de Terapia Ocupacional da USP, São Paulo, v. 24, n. 2, p. 103-11, 2013.

MALFITANO, A. P. S. Campos e núcleos de intervenção na terapia ocupacional social. Revista de Terapia Ocupacional da USP, São Paulo, v. 16, n. 1, p. 1-8, 2005.
MORAIS, A. C. Terapia Ocupacional e medidas socioeducativas em meio aberto: percepçóes e práticas. 2013. 121 f. Dissertação (Mestrado em Terapia Ocupacional) - Universidade Federal de São Carlos, São Carlos, 2013.

MORAIS, A. C.; MALFITANO, A. P. S. Medidas socioeducativas em São Paulo: os serviços e os técnicos. Psicologia e Sociedade, Belo Horizonte, v. 26, n. 3, p. 613-621, 2014.

PICHON-RIVIÈRE, E. Teoria do vínculo. São Paulo: Martins Fontes, 1998.

SALIBA, M. G. O olho do poder: Análise crítica da proposta educativa do Estatuto da Criança e do Adolescente. São Paulo: Editora UNESP, 2006.

SILVA, C. R.; CARDINALLI, I.; LOPES, R. E. A utilização do blog e de recursos midiáticos na ampliação das formas de comunicação e participação social. Cadernos de Terapia Ocupacional da UFSCar, São Carlos, v. 23, n. 1, p. 131-142, 2015.

SPOSITO, M. P. Introdução - espaços públicos e tempos juvenis. In: SPOSITO, M. P. (Org.) Espaços públicos e tempos juvenis: um estudo de ações do poder público em cidades de regióes metropolitanas brasileiras. São Paulo: Global, 2007. p. 5-43.

TEDESCO, S.; LIBERMAN, F. O que fazemos quando falamos em vulnerabilidade? O Mundo da Saúde, São Paulo, v. 32, n. 2, p. 254-260, 2008.

\section{Contribuição dos Autores}

Este estudo é parte da dissertação de mestrado da primeira autora, intitulada "Terapia ocupacional e medidas socioeducativas em meio aberto: percepçóes e práticas", defendida no Programa de Pós-graduação em Terapia Ocupacional da Universidade Federal de São Carlos, em 2013; sob orientação da segunda autora. Todos os autores aprovaram a versão final do texto.

\section{Fonte de Financiamento}

Coordenação de Aperfeiçoamento de Pessoal de Nível Superior - CAPES.

\section{Notas}

${ }^{1}$ Grupo interinstitucional de estudos, pesquisa, formação e açôes pela cidadania de crianças, adolescentes e adultos em processos de ruptura das redes sociais de suporte, sob os pressupostos da Terapia Ocupacional Social, que congrega atualmente núcleos na Universidade Federal de São Carlos (UFSCar), Universidade de São Paulo (USP), Universidade Federal de São Paulo (UNIFESP) e Universidade Federal do Espírito Santos (UFES) (LOPES et al., 2012b).

2 Trata-se de uma entrevista em grupo, que atende a fins específicos em uma investigação, conserva o caráter de uma técnica para coleta de dados qualitativos (KIND, 2004). Optou-se por esta técnica na tentativa de alcançar um discurso coletivo acerca do trabalho do terapeuta ocupacional quando exercendo a função de técnico de referência junto a adolescentes que cumprem medida socioeducativa em meio aberto.

${ }^{3}$ As entrevistadas que participaram do grupo focal foram: E6 (G1), E3 (G2), E8 (G3), E5 (G4) e E4 (G5). 